\title{
Agenda de Federalismo e Relações Intergovernamentais na Diest: novas Perspectivas TEÓRICAS E TEMÁTICAS ${ }^{1}$
}

Paulo de Tarso Frazão Linhares²

Roberto Pires Messenberg ${ }^{3}$

Pedro Palotti ${ }^{4}$

\section{INTRODUÇ̃̃̃O}

O federalismo, enquanto teoria de governo, é considerado por muitos autores como uma discussão eminentemente pragmática, focada em produzir governos autônomos, responsivos e obedientes a limites prévios de atuação constitucional. Seu surgimento histórico no final do século XVIII nos Estados Unidos exemplifica isso. Tratava-se de propor uma engenharia institucional para permitir um governo nacional - a União - ao mesmo tempo em que se mantinha a autonomia dos entes subnacionais.

O contexto histórico de surgimento do federalismo no Brasil difere do americano principalmente por uma inversão de prioridades. $\mathrm{O}$ federalismo aqui foi uma ferramenta institucional de criação de entes subnacionais, o que fortaleceu o papel desempenhado por elites subnacionais na passagem de um Império centralizado aos moldes de um governo unitário para a República (Carvalho, 2001; Stepan, 1999). Mais recentemente, o texto constitucional de 1988, marco institucional do restabelecimento da ordem democrática no Brasil, prestigiou os princípios federativos como um meio para a criação de um Estado mais responsivo aos cidadãos e menos suscetível a retrocessos autoritários. Em todas essas circunstâncias, evidencia-se que as discussóes federativas sempre estiveram atreladas a questôes práticas da vida política nacional.

É essa intermediaçấo entre teoria e prática que se pretende ilustrar neste artigo. A Diretoria de Estudos e Políticas do Estado, das Instituiçóes e da Democracia (Diest) surge no Ipea para contribuir com a reflexão sistemática de questóes que envolvam a interface entre o Estado e a sociedade, promovendo um recorte focado em questôes institucionais que permeiam a "elaboraçáo, implementação, monitoramento e avaliação de políticas públicas para o desenvolvimento do país", conforme o art. 95 do Regimento Interno do Ipea (Brasil, 2017). A agenda sobre o federalismo brasileiro e seu padráo de relaçóes intergovernamentais encaixa-se bem nesse propósito da diretoria.

Após esta breve introdução, a seção 2 dedica-se a compreender a transformação da agenda de estudos sobre federalismo e relaçóes intergovernamentais no Brasil, destacando a passagem de questốes eminentemente fiscais para administrativas, focadas em aspectos institucionais de algumas políticas setoriais e de novos arranjos político-institucionais. A terceira seção irá tratar das contribuiçôes teórico-analíticas e de apoio institucional promovidas pela Diest, destacando-se interseçóes entre ambas. Por fim, nas considerações finais, serão apontadas questôes em aberto e novas reflexões analíticas em curso, com intuito de se esboçar uma agenda futura de pesquisa.

1. DOl: http://dx.doi.org/10.38116/bapi29art10

2. Técnico de planejamento e pesquisa na Diretoria de Estudos e Políticas do Estado, das Instituições e da Democracia (Diest) do Ipea.

3. Técnico de planejamento e pesquisa na Diest/lpea.

4. Especialista em políticas públicas e gestão governamental na Diest//pea. 


\section{PERSPECTIVAS TEÓRICAS PARA A COMPREENSÃO DO FEDERALISMO E DAS RELAÇÕES INTERGOVERNAMENTAIS NO BRASIL}

O federalismo fiscal é uma das perspectivas mais tradicionais para a compreensão do funcionamento das federaçóes. Sua ênfase está em questóes relacionadas à tributação - quem deve tributar, por meio de quais mecanismos, quais as consequências esperadas de alguns instrumentos fiscais - e sobre como os entes federados se organizam para a provisão de bens e serviços. A descentralização fiscal emerge, assim, como uma perspectiva teórica central na busca de respostas a essas questôes, com vistas ao alcance de um estado geral maior de eficiência tributária e bem-estar social (Oates, 1972; Musgrave, 1959).

Discussôes teóricas dessa natureza compóem a caixa de ferramentas de economistas e outros cientistas sociais que formataram os modelos de tributação e redistribuição fiscal adotado nos anos 1960 e 1970, os quais, com incrementos relevantes, mas sem perda de seus fundamentos, acabam por vigorar após a Constituição de 1988. Nesse sentido, a lógica e a participação relativa dos fundos municipais, estaduais e do Distrito Federal mantiveram-se estáveis nas décadas de 1990 e 2000, não obstante as implicaçóes fiscais trazidas pelos novos instrumentos de descentralização e de coordenação federativa. ${ }^{5}$

A dinâmica federativa pós-redemocratização traz novos elementos para a compreensão teórica das relaçóes intergovernamentais. Exemplo disso foi a importância que passou a ser dada aos setores de políticas públicas na distribuiçãao dos recursos fiscais à disposição de cada nível de governo, como nos casos da educação e da saúde. A educação, por exemplo, destaca-se pela existência de um fundo contábil para redistribuição dos recursos disponíveis aos entes subnacionais para educação fundamental (Fundo de Manutenção e Desenvolvimento do Ensino Fundamental e de Valorização do Magistério - Fundef) e, posteriormente, de todo ensino básico (Fundo de Manutenção e Desenvolvimento da Educação Básica - Fundeb). A saúde, embora não conte com um mecanismo contábil e de equalização de receitas, passou a atrelar os repasses da União à organização territorial de novos serviços assistenciais no âmbito do Sistema Único de Saúde (SUS). Uma das normatizações mais abrangentes do ponto de vista fiscal com impacto significativo para os entes subnacionais foi a Lei de Responsabilidade Fiscal (Lei Complementar n⿳ 101/ 2000). Depois dela, outras normatizaçóes impactantes ocorreram sobretudo nas políticas setoriais.

Importa destacar, portanto, um padrão emergente de relaçóes intergovernamentais marcado por maior integração vertical entre os diferentes níveis de governo. A União, seja por meio da atuação dos ministérios do Poder Executivo, seja pela votação de leis de abrangência nacional, consolida-se como um ator central de promoção da coordenação federativa (Abrucio, 2005; Arretche, 2009; 2013; Machado, 2015; Machado e Palotti, 2015; Palotti, 2019). Aos poucos o eixo de reflexóes - e também de mudanças institucionais - deslocou-se dos aspectos tributários e fiscais para a compreensão das relações intergovernamentais no âmbito da federação e das políticas públicas. Na definição conceitual proposta por Falleti (2006), é como se a ênfase se deslocasse da descentralização fiscal

5. Em termos quantitativos, contudo, cabe aqui destacar uma queda pronunciada na participação conjunta das receitas disponíveis da União e dos estados - após as transferências constitucionais (obrigatórias por lei e discricionárias) - a partir de 2017. Assim, ainda que nesse ano a participação relativa da arrecadação tributária bruta da União $(65,8 \%)$ tenha se mantido superior às participações relativas de estados $(27,1 \%)$ e municípios (7,1\%), as parcelas dos recursos líquidos apropriados pela União e pelos estados registraram as magnitudes de $55,1 \%$ e de $25,2 \%$ do total, respectivamente, contra uma ampliação da fatia dos municípios que atingiu algo em torno de 19,7\% do total (Afonso e Castro, 2018). 
para a administrativa, ou seja, o aspecto da descentralização referente à execução propriamente dita das políticas públicas.

Ao mesmo tempo em que aspectos setoriais e de coordenação vertical vão se tornando evidentes para a compreensão da dinâmica federativa brasileira, questóes de coordenação horizontal adentram a agenda de estudos sobre o federalismo no Brasil. Surge uma importante vertente de trabalhos na literatura nacional sobre o funcionamento dos consórcios intermunicipais, seus limites e as possibilidades do fortalecimento de um federalismo de caráter mais cooperativo (Linhares, Mendes e Lassance, 2012; Linhares e Messenberg, 2014; Linhares et al., 2016; Linhares, Messenberg e Ferreira, 2017).

Em particular, como em Carvalho e Afonso (2018), entende-se aqui que a coordenação federativa no Brasil merece especial atenção quando se constata a inexistência de uma instância abrangente de coordenação federativa entre os entes federados. É também a partir dessa perspectiva sobre o novo arranjo político-institucional recentemente estabelecido no Brasil que se pretende compreender a atuação da Diest desde sua criação, em 2009. Na próxima seção, serão destacadas contribuições teóricas e de apoio institucional empreendidas pela diretoria.

\section{CONTRIBUIÇÕES TEÓRICAS E DE APOIO INSTITUCIONAL DA DIEST/IPEA}

A contribuição do Ipea às discussóes sobre federalismo, antes da criação da Diest, estava orientada pela agenda do chamado federalismo fiscal. O principal núcleo dessas pesquisas encontrava-se na Diretoria de Estudos e Políticas Regionais, Urbanas e Ambientais (Dirur) e enfocava, sobretudo, as finanças dos entes subnacionais.

A criação da Diest aportou ao Ipea, sobretudo, a incorporação da análise das relações interfederativas, tanto no plano horizontal quanto vertical. As perspectivas teóricas até então utilizadas passaram a incorporar conceitos e análises advindas principalmente da ciência política. Dessa forma, as pesquisas sobre federalismo conduzidas no âmbito da Diest não buscaram concorrer com a agenda anterior, mas sim complementar e enriquecer a carteira de projetos e as questóes pesquisadas pelo Ipea.

O ambiente governamental, político e acadêmico sobre federalismo também apresentava mudanças naquele momento no Brasil. Após os anos 1990, marcados por intensa competição entre os entes federativos, o tema da cooperaçáo ocupa gradativamente centralidade na primeira década do século XXI. Um exemplo dessa mudança pode ser ilustrado por uma inovação institucional ocorrida em 2005, com a promulgação da lei de consórcios públicos e sua regulamentação no ano seguinte. Esse novo instrumento de cooperação federativa já mostrava os primeiros sinais de sua capacidade de remodelação das relaçóes interfederativas em 2010, quando da criação da Diest.

Nesse contexto, a agenda de atuação da Diest sobre federalismo foi orientada à análise dos elementos institucionais que condicionavam a cooperação e a coordenação dos entes da Federação brasileira, notadamente, da cooperação federativa intermunicipal. Nesse sentido, destaca-se o mapeamento dos consórcios intermunicipais em território nacional, com a revelação de que os consórcios intermunicipais são uma das principais transformaçóes ocorridas no âmbito federativo de nossa administração pública (Linhares, Messenberg e Ferreira, 2017), conforme mostra o gráfico 1. 
GRÁFICO 1

Brasil: consórcios públicos ativos, segundo abertura de Cadastro Nacional de Pessoa Jurídica (CNPJ) (1970-2012)

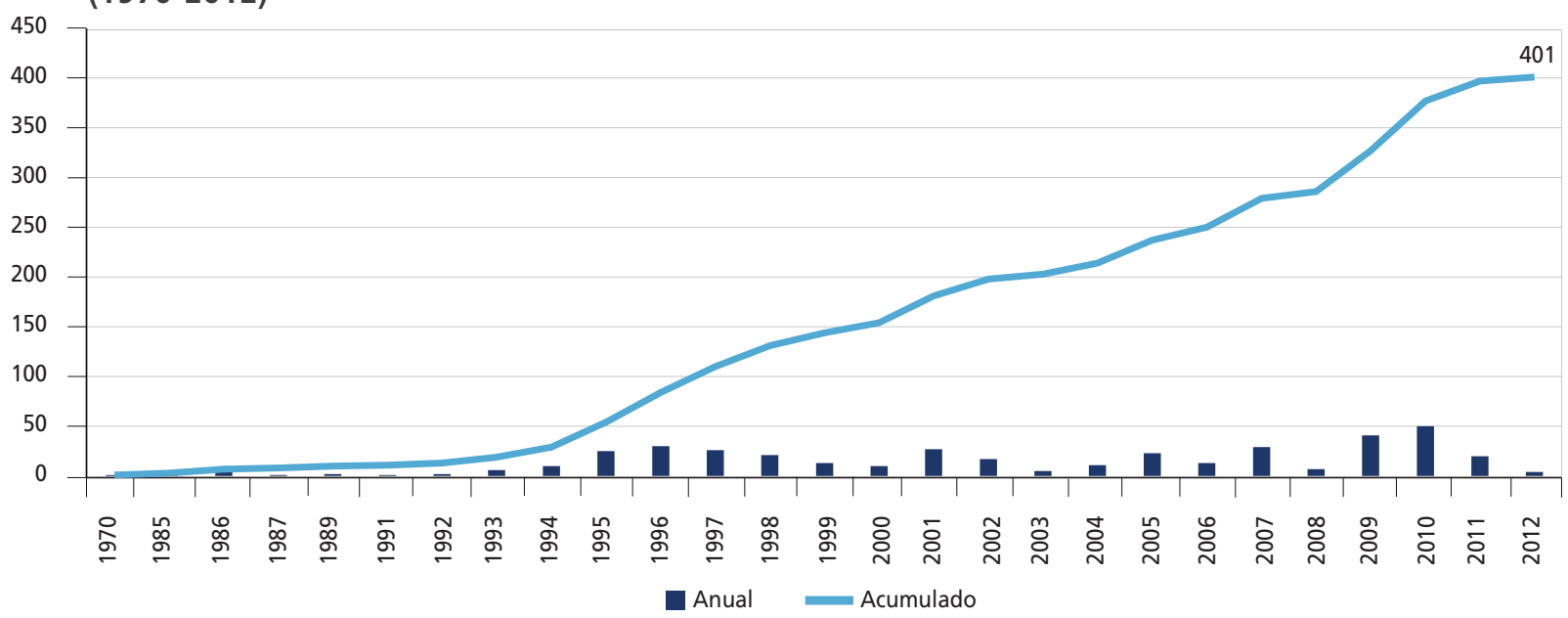

Fonte: Receita Federal, 2012.

$\mathrm{Na}$ trilha aberta por tais estudos, buscou-se então compreender algumas questóes relevantes sobre as razóes dessa forte expansão. Nesse sentido, observou-se uma distribuição heterogênea do instituto em tela entre estados da Federação, evidenciando-se o papel dos governos estaduais na sua adoção pelas unidades municipais. Em termos da incidência, distribuição e atuação do consorciamento intermunicipal por diferentes áreas de políticas públicas no Brasil, os resultados das pesquisas desenvolvidas evidenciaram clara distinção entre as iniciativas na área de saúde e dos demais setores (gráfico 2).

\section{GRÁFICO 2}

\section{Consorciamento intermunicipal no Brasil por tamanho do município (2015)} (Em \%)

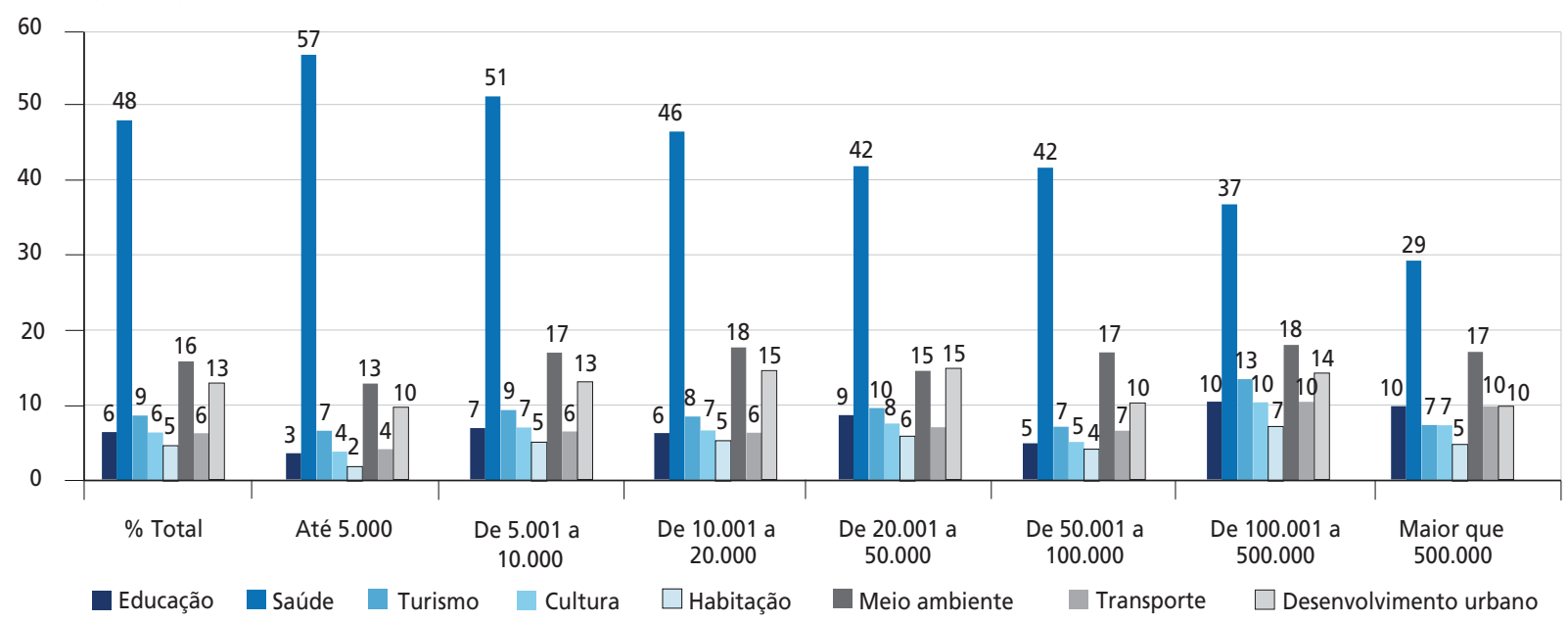

Fonte: Pesquisas de Informações Básicas Municipais do Instituto Brasileiro de Geografia e Estatística (Munic/IBGE). Elaboração dos autores.

Assim, além da expressiva participação dos consórcios de saúde nos municípios brasileiros, é especialmente significativo constatar a existência de uma incidência decrescente dessa modalidade de 
consorciamento, quando o foco analítico é deslocado para faixas de unidades municipais mais populosas. Tal constatação constitui forte evidência da busca por economia de escala na constituição de consórcios intermunicipais de saúde.

Desse modo, a observação do processo de formação de consórcios em distintas áreas de políticas públicas permitiu concluir que a descentralização, por um lado, e a fragmentação, por outro, constituem os principais fatores de impulsão do movimento de consorciamento intermunicipal desde os anos 1990. Atualmente, no caso da saúde - em contraposição às demais áreas de política pública -, a intensidade do movimento de consorciamento tende a estabilizar-se, uma vez que o movimento de descentralização promovido com a implantação do Sistema Único de Saúde (SUS) encontra-se consolidado - assim como o processo de fragmentação municipal (Linhares, Messenberg e Ferreira, 2017).

Em outra vertente, a agenda de pesquisa sobre federalismo na Diest analisou a cooperação vertical por meio dos investimentos em infraestrutura com recursos federais realizados por municípios. Nesse campo de trabalho, três resultados principais merecem menção. Em primeiro lugar, contrariando conclusóes da literatura sobre descentralização, constatou-se que a ação dos municípios é menos eficiente do que a literatura sugere. Todavia, quando são investigadas as condiçóes conducentes ao melhor desempenho dos municípios, constata-se sua dependência ao grau de estruturação da administração pública e à intensidade do ativismo da sociedade civil. Essas duas características podem ajudar os gestores dos programas do governo federal a desenvolver estratégias para superar as dificuldades nos casos em que elas se apresentam de maneira mais aguda.

Um segundo achado relevante diz respeito à destinação dos recursos. Contrariando o que a literatura especializada recomenda, a observação indica uma tendência à destinaçáo de recursos federais aos municípios menos necessitados. Nesse aspecto, um terceiro achado revelou que os projetos apoiados por emendas parlamentares são os que mais atendem o princípio distributivo na destinação desses recursos. Ou seja, atendendo a uma racionalidade compreensível do ponto de vista político, parlamentares destinam recursos a municípios necessitados e populosos.

Por fim, a emergência da pandemia do novo coronavírus exigiu um redirecionamento do esforço de pesquisa. Foram analisados os diferentes arranjos de coordenação federativa implementados pelos estados brasileiros e, especialmente, como e com que intensidade foram incorporados representantes de governos municipais e da sociedade civil (Linhares, Ramos e Messenberg, 2020).

\subsection{Parcerias institucionais}

A atuação da Diest na área de pesquisa sobre federalismo não se restringiu à produção interna de textos analíticos: diversas parcerias foram estabelecidas. A primeira e mais profícua delas ocorreu no âmbito do próprio Ipea. Por meio da criação do Grupo de Trabalho (GT) interdiretorias sobre federalismo, estabeleceu-se entre pesquisadores uma agenda de trabalho que permitiu a atuação conjunta da Diest com as demais diretoriais, em especial, a Dirur. E foi frequentemente por meio do GT que a Diest impulsionou diversas iniciativas de pesquisa sobre federalismo no âmbito do Ipea.

Nesse sentido, destacam-se, por exemplo, os debates que antecederam ao plebiscito sobre a divisão do estado do Pará e a criação de três novos estados na Federação brasileira em 2011. Já em parceria com o Instituto de Desenvolvimento Econômico-Social do Pará, deve-se mencionar que dois técnicos do Ipea participaram dos debates naquele momento. O Ipea aportou ao debate estimativas 
sobre como as mudanças propostas afetariam a representação política na Câmara dos Deputados e no Senado Federal, com a consequente remodelação da federação brasileira; e os cálculos dos custos decorrentes da criação dos novos estados. Em outra oportunidade, merece destaque ainda o fato de o Ipea sediar um seminário com a participação de parlamentares paraenses (pró e contra) a divisão do Pará. A partir dessas contribuições, evidenciou-se, então, que a criação dos novos estados traria aumento do gasto público e sobrerrepresentação eleitoral, sobretudo no Senado, de regióes com forte presença de atividades madeireiras e de mineração.

Finalmente, não se pode deixar de mencionar o conjunto de estudos elaborados por diferentes pesquisadores do Ipea e de outras instituiçóes associados em função de convite do GT interdiretorias sobre federalismo e cujas atividades culminaram na publicação do livro Federalismo à Brasileira: questóes para discussão (Linhares, Mendes e Lassance, 2012). ${ }^{6}$

\subsection{Assessoramento ao governo federal}

A Emenda Constitucional no 95/2016 estipulou a necessidade de regulamentação das regras para a criação de novos municípios no Brasil. Nesse sentido, a Presidência da República requisitou ao Ipea que subsidiasse na elaboração da norma. Dois técnicos da Diest foram assim indicados, como integrantes de uma comissão da Presidência da República, juntamente com representantes de outros órgãos, para a elaboração da norma.

Em outra iniciativa, a Frente Nacional de Prefeitos criou o Observatório dos Consórcios Públicos e do Federalismo e, por meio de um Acordo de Cooperação Técnica, escolheu o Ipea como membro do observatório na qualidade de coordenador da assessoria técnica. No âmbito dessa cooperação, diversos seminários foram realizados com vistas à pesquisa de abrangência nacional sobre a formação de consórcios públicos intermunicipais.

O tema da coordenação federativa também foi objeto de uma cooperação internacional com o Fórum das Federaçóes. No âmbito dessa iniciativa foram desenvolvidos estudos envolvendo pesquisadores de diversos países latino-americanos (Argentina, Venezuela e Colômbia) para a identificação e um esforço analítico comparado sobre as principais características dos arranjos federativos nacionais. Desse esforço conjunto resultou a realização de um colóquio na sede do Ministério das Relaçóes Exteriores, em Brasília, com participação de pesquisadores dos três países e representantes do governo federal e pesquisadores brasileiros. A partir das discussóes ocorridas no colóquio e de outras que se seguiram, foi elaborada a publicação do livro Federalismo Sulamericano. Nele, buscou-se consolidar alguns elementos definidores do momento atual dos arranjos federativos argentino, venezuelano e colombiano.

\section{CONSIDERAÇÕES FINAIS}

Seguindo as origens históricas do federalismo, é natural que essa agenda de pesquisa esteja imersa em questóes práticas pertinentes às relaçóes intergovernamentais, seja entre entes federados no mesmo nível de governo (horizontal), seja entre governos de diferentes níveis (vertical). A trajetória da Diest apontada neste artigo confirma essa perspectiva, de modo que problemas reais de políticas públicas foram incorporados na agenda de pesquisa da diretoria e contribuíram para trazer reflexôes pertinentes ao campo. Além disso, ilustra a inserção de preocupações e recortes típicos da ciência política - em

6. Posteriormente, a publicação ganhou versão em inglês sob o título Brazilian Federalism: issues for discussions. 
particular, de sua vertente neo-institucionalista -, um enquadramento analítico inovador para os trabalhos desenvolvidos no instituto.

Como agenda futura de pesquisa, algumas questóes têm se mostrado relevantes tanto do ponto de vista teórico, como político. Uma primeira reflexão diz respeito ao papel desempenhado pelos estados na Federação brasileira. Essa é uma questão especialmente desafiadora, posto que em praticamente todas as Federaçóes no mundo os governos locais não possuem autonomia política, como no Brasil. Isso permitiu que, no plano federal, os governos que se seguiram à Constituição de 1988 enfatizassem suas relações diretas com os municípios. As renegociaçóes das dívidas estaduais, durante a década de 1990, associadas à Lei de Responsabilidade Fiscal, restringiram a autonomia fiscal dos estados, o que não impediu que muitos deles tenham atingido uma situação de insolvência trinta anos depois. O início dos anos 2020 apresentam não apenas um enorme desafio imposto pela pandemia do novo coronavírus, mas a necessidade de compreender melhor o papel potencial dos estados para consolidação de um conjunto de serviços públicos direcionados à população.

A retomada de uma reflexão sobre a atuação dos estados na federação brasileira implica o resgate de parte do debate teórico central do federalismo fiscal. Sem se ignorar os ganhos efetivos da coordenação federativa promovida nos últimos trinta anos, algumas discussóes de natureza estruturante do aspecto econômico e das desigualdades entre os entes federados tornam-se naturalmente mandatórias. Dado o estágio de normatização e o padrão mais centralizado de funcionamento do federalismo brasileiro, é de esperar que propostas de reforma do pacto federativo sejam debatidas pela União. A remodelagem da Federação significa ampliar a autonomia, mas também as responsabilidades dos entes subnacionais, sobretudo dos estados, na provisão de políticas públicas.

Atrelado a aspectos mais políticos do pacto federativo, cabe destacar uma agenda de pesquisa que possa investigar como fortalecer a coordenaçáo federativa sem diminuir o protagonismo político dos entes federados. O Brasil destaca-se como uma das federaçóes mais abrangentes e complexas sem fóruns de coordenação federativa. Durante um curto período, o extinto Comitê de Articulação Federativa $(\mathrm{CAF})$ procurou desempenhar esse papel, restringindo-se à União e aos municípios. Há em funcionamento comissóes dedicadas a produzir decisóes conjuntas e acordadas entre os entes federados, mas restritas a setores de políticas públicas como a saúde e a assistência social. Algumas reflexôes já estão em curso, o que torna promissora essa agenda (Jaccoud, 2020).

\section{REFERÊNCIAS}

ABRUCIO, F. L. A coordenação Federativa no Brasil: a experiência do período FHC e os desafios do governo Lula. Revista de Sociologia e Política, n. 24, p. 41-67, 2005.

AFONSO, J. R. R.; CASTRO, K. Arrecadação tributária brasileira: uma avaliação atualizada. Cadernos FGV Projetos, n. 13, p. 62-77, 2018.

ARRETCHE, M. Continuidades e descontinuidades da Federação brasileira: de como 1988 facilitou 1995. Dados, n. 52, p. 377-423, 2009. 
Quando instituições federativas fortalecem o governo central? In: HOCHMAN, G.; FARIA, C. A. P. de (Org.). Federalismo e políticas públicas no Brasil. Rio de Janeiro: Editora Fiocruz, 2013. p. 65-90.

BRASIL. Ministério do Planejamento, Desenvolvimento e Gestão. Portaria no 207 , de 5 de junho de 2017. Editar o Regimento Interno do Instituto de Pesquisa Econômica Aplicada - Ipea, na forma do Anexo I a esta Portaria. Diário Oficial da União, Brasília, 8 jun. 2017.

CARVALHO, C. M. S.; AFONSO, J. R. R. Coordenação e relações intergovernamentais em federações avançadas: algumas liçóes para o Brasil. Revista Jurídica Luso-Brasileira, n. 4, p. 1571-1604, 2018.

CARVALHO, J. M. de. Cidadania no Brasil: o longo caminho. Rio de Janeiro: Civilização Brasileira, 2001.

FALLETI, T. Efeitos da descentralização nas relações intergovernamentais: o Brasil em perspectiva comparada. Sociologias, n. 8, v. 1, p. 46-85, 2006.

JACCOUD, L. (Org.). Coordenação e relaçóes intergovernamentais nas políticas sociais brasileiras. Brasília: Ipea, 2020.

LINHARES, P. et al. Cooperação vertical em investimentos federais realizados por municípios. Boletim de Análise Político-Institucional, n. 9, 2016.

LINHARES, P.; MENDES, C.; LASSANCE, A. (Org.). Federalismo à brasileira: questóes para discussáo. Brasília: Ipea, 2012. v. 8. (Diálogos para o Desenvolvimento).

LINHARES, P.; MESSENBERG, R. Consórcios e características municipais: avanços na cooperação federativa? Boletim de Análise Político-Institucional, n. 6, 2014.

LINHARES, P.; MESSENBERG, R.; FERREIRA, A. P. Transformaçóes na Federação brasileira: o consórcio intermunicipal no Brasil do início do século XXI. Boletim de Análise Político-Institucional, n. 12, 2017.

LINHARES, P.; RAMOS, T. Q.; MESSENBERG, R. P. (2020). Inovação institucional na coordenação federativa para o enfrentamento e saída do surto de Covid-19. Brasília: Ipea, 2020. (Nota Técnica, n. 41).

MACHADO, J. A. Padróes de indução de políticas sociais por meio de transferências intergovernamentais condicionadas. Teoria e Sociedade, n. 19, v. 22.1, p. 191-218, 2015.

MACHADO, J. A.; PALOTTI, P. L. M. Entre cooperação e centralização: federalismo e políticas sociais no Brasil pós-1988. Revista Brasileira de Ciências Sociais, n. 30, v. 88, p. 61-82, 2015.

MUSGRAVE, R. M. The theory of public finance. New York: McGraw-Hill, 1959.

OATES, W. E. Fiscal federalism. New York: Harcourt Brace Jovanovich, 1972.

PALOTTI, P. Federalism, Brazil: global encyclopedia of public administration, public policy, and governance. Springer International Publishing, p. 1-7, 2019. DOI: 10.1007/978-3-319-318165_3753-1.

STEPAN, A. Para uma análise comparativa do federalismo e da democracia: federaçóes que restringem ou ampliam o poder do demos. Dados, n. 42, v. 2, p. 1-37, 1999. 